Лежебоков Андрей Александрович

доктор социологических наук, профессор кафедры социологии

Северо-Кавказского федерального университета

\section{СОЦИАЛЬНОЕ САМОЧУВСТВИЕ НАСЕЛЕНИЯ СТАВРОПОЛЬСКОГО КРАЯ В 2017 Г. (ПО РЕЗУЛЬТАТАМ СОЦИОЛОГИЧЕСКОГО ИССЛЕДОВАНИЯ) [1]}

\section{Аннотация:}

В статье изложены результаты проведенного с участием автора социологического исследования социального самочувствия населения Ставропольского края, описаны ключевые показатели отношения граждан к социальной действительности, определены перспективы дальнейшего анализа социокультурного развития региона. Теоретический фундамент работы представлен социокультурным подходом, эмпирическая часть реализована на территории края с учетом возрастных, половых, регчональных квот. Обработка результатов проведена с помощью общепринятых программных средств. Социальное самочувствие граждан края оценивали с помощью данных, показывающих оmношение жителей региона к месту жительства, окружающим людям, региону в целом. Интересной представляется позиция респондентов к перспективам развития территории и своему будущему. Установлено, что для выявления более глубоких зависимостей, а также динамики социокультурных процессов необходимо регулярно обращаться к подобным исследованиям.

\section{Ключевые слова:}

социальное самочувствие, качество жизни, социологический опрос, Ставропольский край, население региона, социокультурное развитие.
Lezhebokov Andrey Aleksandrovich

D.Phil. in Social Science, Professor, Sociology Department, North-Caucasus Federal University

THE SOCIAL WELL-BEING OF THE STAVROPOL TERRITORY POPULATION IN 2017 (BASED ON SOCIOLOGICAL STUDY RESULTS) [1]

Summary:

The study presents the findings of the sociological study on the social well-being of the Stavropol Territory population. It describes the key indicators of citizens attitudes towards social reality and outlines the prospects for further research on the social and cultural development in this region. The theoretical foundation of the research is a sociocultural approach. An empirical study is carried out in the Stavropol Territory taking into account age, sex, and territorial quotas. The results obtained are processed with the help of generally accepted software. The social well-being of the citizens is assessed through their attitude towards the place of residence, other people, and the region in general. The viewpoint of respondents on the prospects of territorial development and their future is of great interest. The author concludes that such surveys are necessary to reveal other correlations and the dynamics of social and cultural processes.

Социальное самочувствие населения региона является важной характеристикой уровня развития субъекта Российской Федерации. Актуальность регулярных исследований данного показателя определяется необходимостью определения тенденций социокультурной динамики общества, а также выявления факторов, оказывающих влияние на мировоззренческие установки граждан. Помимо исследовательского интереса изучение самочувствия населения обусловлено и рядом практических задач. Прежде всего это связано с тем, что в системе государственного и муниципального управления выводы по результатам опросов потенциально позволяют соответствующим структурам вносить коррективы в планы и программы дальнейшего обустройства территории, повышения качества жизни. Проблематика анализа социального самочувствия включает в себя разные пространственные уровни, например отдельного города или разных стран [2], и может связываться с разнообразными факторами [3].

Теоретической основой исследования социального самочувствия населения в нашей работе выступил социокультурный подход в его антропосоциетальной модификации, представленной в работах научного коллектива под общим руководством Н.И. Лапина и Л.А. Беляевой [4] и апробированной в исследовательских проектах в ряде регионов России. Это, впрочем, не умаляет большой эвристический потенциал других парадигмальных программ, например огромные возможности имеют структурно-функциональный, системный, субъектно-деятельностный подходы. Социокультурный подход позволяет изучить регион как отдельную территориальную общность - сообщество, образованное совокупностью взаимодействия социальных субъектов. Следовательно, уникальные для местности характеристики, позволяющие своим носителям - индивидам, социальным группам - как в структуре регионального пространства, так и за его пределами действовать эффективно, являются основным направлением анализа. Для обоснования таких характеристик и, что 
самое главное, поиска закономерностей их влияния на предмет изучения традиционно осуществляется процедура сравнения определенных параметров региона с соответствующими показателями соседних территорий или со средними данными по стране в целом.

Исследование социального самочувствия населения в Ставропольском крае представлено в виде одного из блоков социологической анкеты, с помощью которой проведен опрос жителей региона. Тип выборочной совокупности - квотный, по возрасту, полу, типу местности (городская, сельская), выборка составила $\mathrm{N}=996$ в соответствии с данными социально-демографической статистики. Основной задачей является составление комплексного социального портрета жителей края на основе репрезентативных данных, в том числе полученных с помощью опросных методов. Статистической обработке с использованием пакета SPSS были подвергнуты анкеты 996 жителей, из которых мужчины составили 43,7 \%, женщины - 56,3. По месту проживания 32,5 \% опрошенных жители сел, деревень; 8,1 - рабочих поселков; остальные 59,4 \% - горожане. Опрос осуществляли более чем в 50 населенных пунктах, структура занятости респондентов приведена в таблице 1.

\section{Таблица 1 - Распределение ответов респондентов на вопрос} относительно занятости в настоящее время, \%

\begin{tabular}{|l|c|}
\hline \multicolumn{1}{|c|}{ Варианты ответов } & Количество ответивших \\
\hline работаю на постоянной основе & 56,6 \\
\hline временно не работаю & 3,5 \\
\hline имею статус неработающего пенсионера, инвалида & 12,8 \\
\hline не работаю & 5,2 \\
\hline не работаю, но активно ищу постоянную или временную работу & 4,6 \\
\hline учусь в учебном заведении на дневной фрорме обучения & 10,6 \\
\hline затрудняюсь ответить / отказ от ответа & 4,6 \\
\hline
\end{tabular}

Уровень образования респондентов характеризуется следующими цифрами, \%: не имеют образования либо имеют начальное или неоконченное среднее - 7,3; среднее общее образование - 15,8; начальное и среднее специальное - 27,8 (из них среднее специальное - 24,0); неоконченное высшее - 11,9; высшее - 32,2; имеют послевузовское образование - 2,5; столько же уклонились от ответа. Национальный состав опрошенных выражен 25 этническими группами, но большинство - 87,5 \% - указали принадлежность к русским.

Социальное самочувствие населения определяли по большому блоку вопросов. Наиболее интересной, по нашему мнению, является общая оценка качества жизни граждан Ставропольского края по сравнению с соответствующим показателем для соседних регионов. Так, однозначная уверенность в том, что жители края живут лучше, чем граждане соседних местностей, фиксируется у 18,9 \% опрошенных; противоположное мнение наблюдается у 11,8 \% ответивших; 54,4 \% считают, что по сравнению с одними регионами в крае люди живут лучше, а с некоторыми другими - хуже. Довольно большая доля респондентов затруднились ответить на данный вопрос - 13,5 \%; отказались от ответа - 1,4\%.

Таким образом, больше половины ответивших занимают достаточно взвешенную позицию в данном вопросе, поскольку не выделяют условия проживания в крае как «лучшие» или «худшие». Привлекательными чертами региона респонденты считают природу (46,3 \%) и наличие рядом добрых, душевных людей (24,3%). Вместе с тем только 10,4 \% считают Ставропольский край перспективным для жизни, 7,7 \% видят на территории региона возможности для инициативных людей. Однако, описывая непривлекательные черты региона, 12,6 \% опрошенных отметили, что край имеет слишком суровый климат, 16,1 - «люди у нас неприветливы», 25,6 - «жизнь здесь заглохла», 12,4 \% - «инициативу тут не любят».

Ответы респондентов на вопрос: «Какие чувства Вы испытываете по отношению к региону?» - распределились следующим образом. Почти треть опрошенных - 30,6 \% - рады, что живут на территории Ставропольского края. В целом выражают удовлетворение 41,9 \% ответивших, но вместе с тем многое их не устраивает. Не испытывают особых чувств по отношению к региону 15,4 \%, при этом 4,8 \% отметили, что им не нравится здесь жить, но они ко всему привыкли и не собираются уезжать в другое место. Только 3,7 \% сообщили, что хотят уехать в другие субъекты Российской Федерации, а 1,2 \% - из страны вообще. Затруднились с ответом или отказались отвечать на данный вопрос 2,4 \% участников выборки. Эти результаты позволяют оценить отношение населения к Ставропольскому краю как в целом положительное.

Опрошенным свойственно традиционное мировоззрение по отношению к окружающим их людям: чем больше дистанция до других, тем меньше респонденты испытывают чувство близости к ним. Это очевидно из данных, приведенных в таблице 2. 
Таблица 2 - Распределение ответов респондентов на вопрос: «Чувствуете ли Вы близость со следующими категориями людей?», \%

\begin{tabular}{|l|c|c|c|}
\multicolumn{1}{|c|}{ Категории людей } & \multicolumn{2}{|c|}{ Варианты ответов } \\
\cline { 2 - 4 } & да & нет & $\begin{array}{c}\text { трудно сказать / } \\
\text { не знаю }\end{array}$ \\
\hline $\begin{array}{l}\text { жители поселения, в котором проживает респон- } \\
\text { дент (деревня, село, город) }\end{array}$ & 66,8 & 15,9 & 17,3 \\
\hline жители Ставропольского края & 37,5 & 34,7 & 27,7 \\
\hline жители Северо-Кавказского фредерального округа & 23,9 & 41,3 & 34,9 \\
\hline жители всей России & 26,4 & 37,4 & 36,3 \\
\hline жители бывших республик СССР & 21,6 & 42,0 & 36,4 \\
\hline жители всей Земли & 18,0 & 43,1 & 38,9 \\
\hline
\end{tabular}

Как видим, по мере «удаленности» от места непосредственного социального окружения респонденты показывают резкое ослабление чувства близости по отношению к другим людям. Современные информационные технологии не могут «восполнить дефицит непосредственного эмоционального общения "лицом к лицу"» [5]. Интересно, что схожие значения получены относительно таких категорий, как «жители бывших республик СССР» и «жители всей Земли», что позволяет говорить об усугубляющемся отдалении народов республик бывшего Советского Союза друг от друга.

Важнейшим показателем социального самочувствия является уверенность населения в будущем. Результаты опроса подтверждают, что респонденты в целом довольно оптимистичны в данном отношении. Так, 25,4 \% опрошенных выразили уверенность в будущем; 24,9 \% сообщили, что они «скорее уверены, чем нет»; 28,8 \% не могли точно утверждать. Совершенно не уверены в будущем только 6,5 \% ответивших; «скорее не уверены, чем уверены» 12,8 \%; отказались от ответа $1,6 \%$. Схожая картина наблюдается и при анализе ответов относительно удовлетворенности жизнью в целом. Полностью удовлетворены $25,6 \%$; еще $38,0 \%$ ответили, что «скорее удовлетворены». «Совсем не удовлетворены» только 5,0\%; «не очень удовлетворены» 14,3\%; затруднились ответить на этот вопрос 15,4 \%; отказались от ответа 1,7 \% участников исследования.

Показательно, что респонденты в основном полагаются на собственные силы, отвечая на вопрос относительно источников улучшения жизни (таблица 3 ).

Таблица 3 - Распределение ответов респондентов на вопрос: «В какой степени улучшение Вашей жизни сегодня зависит от... ?», \%

\begin{tabular}{|l|c|c|c|c|c|}
\hline \multirow{2}{*}{ Источники улучшения жизни } & \multicolumn{5}{|c|}{ Варианты ответов } \\
\cline { 2 - 6 } & $\begin{array}{c}\text { полностью } \\
\text { зависит }\end{array}$ & $\begin{array}{c}\text { пожалуй, } \\
\text { зависит }\end{array}$ & $\begin{array}{c}\text { не знаю, } \\
\text { трудно сказать }\end{array}$ & $\begin{array}{c}\text { пожалуй, } \\
\text { не зависит }\end{array}$ & $\begin{array}{c}\text { совсем зависит } \\
\text { не зави }\end{array}$ \\
\hline сам респондент & 67,6 & 21,3 & 6,0 & 3,4 & 1,7 \\
\hline близкие родственники & 24,9 & 47,0 & 16,2 & 8,3 & 3,6 \\
\hline друзья, земляки & 12,4 & 25,8 & 29,5 & 19.9 & 12,3 \\
\hline начальство & 18,3 & 33,4 & 24,4 & 12,2 & 11,7 \\
\hline районные, городские власти & 16,7 & 31,7 & 28,5 & 12,9 & 10,5 \\
\hline краевые власти & 19,1 & 27,5 & 30,1 & 12,1 & 11,2 \\
\hline общероссийская власть & 24,0 & 30,1 & 25,2 & 10,2 & 10,4 \\
\hline
\end{tabular}

Сравнивая свое нынешнее положение с ситуацией годичной давности, респонденты указывают, что стали жить намного лучше $(12,2$ \%) или несколько лучше $(19,0)$. При этом 40,9 \% опрошенных отметили, что у них ничего не изменилось; несколько хуже стали жить 19,4 \%; намного хуже - 3,4 \%. Однако определяя будущее на год вперед, участники исследования более позитивны: 17,3 \% ответивших заявили, что будут жить значительно лучше; 16,9 - несколько лучше; 28,1 считают, что в их жизни ничего не изменится; 6,6 - несколько хуже; 2,0 \% - значительно хуже. Настораживает тот факт, что, сопоставляя прошлый год с настоящим, только 5,1\% респондентов затруднились с ответом, а при прогнозах на будущий год - уже 26,5 \%. Однако данная цифрра в целом коррелирует с числом людей, которые не смогли ответить относительно уверенности в будущем (28,8 \%). Это подтверждает наличие неясных перспектив у почти трети опрошенных.

Подводя итоги социологического исследования, можно сделать следующие выводы. Вопервых, жители Ставропольского края показывают в целом позитивное отношение к социальной реальности и комплексу условий, в которых они живут и осуществляют социальные взаимодействия. Во-вторых, респонденты демонстрируют потенциал развития собственной активности, однако не могут найти применения своим силам при сложившейся экономической ситуации. Скорее, это связано с остающейся аграрной специализацией региона и проявлениями экономического кризиса. В-третьих, наблюдается высокий уровень рационализации, связанный с оценками собственного участия в социальных практиках и определения перспектив. 
Вместе с тем полагаем, что без сравнения динамики показателей социального самочувствия населения за несколько периодов, охватывающих определенное число лет, а также без сопоставления с данными соседних регионов и России в целом полученные сведения представляют интерес только в качестве основы для дальнейших исследований. Перспективы продолжения работы мы связываем именно с регулярностью проведения подобных социологических опросов, а также привлечением результатов аналогичных выборок по другим регионам.

\section{Ссылки и примечания:}

1. Статья подготовлена в рамках реализации проекта РГНФ № 17-03-002-59 «Перспективы социокультурного развития Ставропольского края».

2. Joshanloo M., Lamers S.M.A. Reinvestigation of the factor structure of the MHC-SF in the Netherlands: Contributions of exploratory structural equation modeling // Personality and Individual Differences. 2016. Vol. 97. P. 8-12.

3. Stern M.J., Seifert S.C. The Social Wellbeing of New York City's Neighborhoods: The Contribution of Culture and the Arts [Электронный ресурc]. URL: http://repository.upenn.edu/siap_culture_nyc/1 (дата обращения: 08.11.2017).

4. Проблемы социокультурной модернизации регионов России / под общ. ред. Н.И. Лапина, Л.А. Беляевой. М., 2013 ; Регионы в России: социокультурные портреты регионов в общероссийском контексте / сост. и ред. Н.И. Лапин, Л.А. Беляева. М., 2009.

5. Сергодеева Е.А., Монастырская Н.И. Индивидуализация vs массовизация: парадоксы современного общества // Общество: философия, история, культура. 2017. №. 8. С. 24.

\section{References:}

Joshanloo, M \& Lamers, SMA 2016, 'Reinvestigation of the factor structure of the MHC-SF in the Netherlands: Contributions of exploratory structural equation modeling', Personality and Individual Differences, vol. 97, pp. 8-12. https://doi.org/10.1016/j.paid.2016.02.089.

Lapin, NI \& Belyaeva, LA (comps.) (eds.) 2009, Regions in Russia: social and cultural profiles of regions in the all-Russian context, Moscow, (in Russian). sian).

Lapin, NI \& Belyaeva, LA (eds.) 2013, Problems of social and cultural modernization of Russian regions, Moscow, (in Rus-

Sergodeeva, EA \& Monastyrskaya, NI 2017, 'Individualization vs massification: the paradoxes of modern society', Obshchestvo: filosofiya, istoriya, kul'tura, no. 8, p. 24. https://doi.org/10.24158/fik.2017.8.4.

Stern, MJ \& Seifert, SC 2017, The Social Wellbeing of New York City's Neighborhoods: The Contribution of Culture and the Arts, viewed 08 November 2017, <http://repository.upenn.edu/siap_culture_nyc/1>. 